\title{
An Exploratory Study on The Relationship Between CEO power and CEO-worker pay ratio: A Multi-dimensional Perspective
}

\author{
Changzheng Zhang ${ }^{1, a}$, Yuefan $L^{1, b^{*}}$ and Yue You ${ }^{1, c}$ \\ ${ }^{1}$ Xi'an University of Technology, School of Economics \& Management, Xi'an China \\ azcz7901@163.com, ${ }^{\text {b*561245907@qq.com, }{ }^{c} 18706718018 @ 163 . c o m}$
}

Keywords: CEO power; CEO-worker pay ratio (CWPR); Multi-dimensional Perspective

\begin{abstract}
In recent years, too large CEO-worker pay ratio (CWPR) has been increasingly questioned, especially it is true in China. With the steady improvement of the corporate governance mechanism, practically the government departments have issued a serious of remuneration control policies, and theoretically the research on the CEO power and CWPR has drawn widespread attention from the academic circles. However, the past literature mainly focused on either the industry-level or firm-level indicators of CEO power, while ignoring the multiple-dimensional nature of CEO power. Based on the review of the existing literature, this paper decomposes the concept of CEO power into four different dimensions, respectively CEO power derived from industry features (CPIF), CEO power derived from legitimate positions (CPLP), CEO power derived from operable resources (CPOR), CEO power derived from share ownership (CPSO), and further discusses the effect of each dimension on the formation of CWPR respectively from the multi-dimensional perspective. The greatest contribution of this paper is to find that effects of different dimensions of CEO power on CWPR have distinct intensities, because of different motives.
\end{abstract}

\section{Introduction}

CEO-worker pay ratio (CWPR) has been a major problem and challenge in improving workers' salaries, job satisfaction, and perceived fairness as the executives of large corporations are compensated at the cost of paying workers better salaries and improving their working conditions, and subsequently, their standard of living through opportunities for both professional and social mobility. The larger the CWPR is, the less it will be available for investment in rewarding workers for their contributions to the company's performance, growth and the achievement of strategic goals. For example, Sreedhari [1](2011) looked for the correlations between CWPR and how employees are treated. The key finding is that the larger the disparity between executive pay and that of the typical employees is, the more likely employees are to be mistreated. The basic logic behind such a finding is that the larger the pay gap is, the more likely executives are to be arrogant and dictatorial. Donovan A. McFarlane[2] (2015) examined the gap in chief executive officer (CEO) and worker compensation by exploring the vital data of 10 corporations about the differences in hourly compensation between CEO and average hourly pay of workers. The author indicated that excessive CWPR is a major organizational challenge that affects perceptions of fairness by stakeholders, especially employees whose contributions to organizational performance and success are not adequately rewarded, instead, being owed to executives as companies increase revenues and profits through the sweat and toil of ordinary workers.

Therefore, it is an urgent thing to enhance the policy effectiveness in controlling or optimizing CWPR in China by enriching the theoretical research within the background of Chinese companies. Among the various theoretical perspectives being applied in investigating this issue, CEO power theory has gradually taken the dominant role and been more and more widely used in this topic. Because of the special status of CEOs in the corporate governance structure, they inevitably have various discretion which can dominate the majority of resources within the company. So that the executives can obtain satisfactory but not optimal in terms of shareholder remuneration contract. CEO power theory actually improves the research effectiveness of the forming mechanism of 
CWPR in many aspects. This study tries to move this research trend further by decomposing the concept of CEO power into four different dimensions, respectively CEO power derived from industry features (CPIF), CEO power derived from legitimate positions (CPLP), CEO power derived from operable resources (CPOR), CEO power derived from share ownership (CPSO). The study discusses the effect of each dimension on the formation of CWPR respectively.

The contribution of this study is of important original value since it is the first study that really considers the multi-dimensional nature of CEO power. The next parts of the paper are arranged as follows. Part II makes a literature review on the relationship between CEO power and CWPR; Part III analyzes the effect of each dimension of CEO power on CWPR; Part IV is the conclusions.

\section{Literature Review on the Relationship between CEO Power and CWPR}

CEO power approach, which can be termed as "CEO discretion approach", "managerial discretion" or "managerial power" in a much wider perspective, views executive compensation not only as a critical instrument for dealing with agency problems, but also as a potential part of the agency problem itself. Because executives seem to have substantial discretion/power over their own and employees' pay, as the discretion increases, so does their ability to extract greater rents both from the benefits originally belonging to shareholders and the employees. A major component of the CEO power approach is the 'outrage' costs and constraints. This constraints are based on how much outrage a proposed CWPR is expected to cause with shareholders, employees and relevant outsiders. The more outrage that is expected, the less likely the directors will be to approve the distorted arrangement in order to avoid embarrassment or reputation harm. So they may take some invisible behaviors, such as non monetary income which is hard to observed, or adjust the corporate profits by means of earnings management to whitewash performance. In addition, improving the pay level of other management members is also one feasible method, because under strong constraints by stakeholders and high 'outrage' costs, the CEO who have greater power will cover up his own too much pay by improving other members' pay. (Shao Bin, Duan Yanxia, Zhang Jinyu, \& Gao Chuang $2014)^{[3]}$. There is an evidence that suggests CWPR arrangements are indeed influenced by outsider and employees perception. This 'outrage' pillar of the CEO power approach enforce executives to try to obscure or camouflage their extraction behavior of rents to avoid the previously discussed 'outrage'. It helps to explain many otherwise unexplainable issues in CWPR practices.

As the two earlier studies discussing the forming mechanism of CWPR from the perspective of CEO power, Wade, J. B. ${ }^{[4]}(2006)$ and Lu Rui ${ }^{[5]}(2007)$ respectively took American and Chinese firms as the sample and explored the static reasons of CWPR. Both of them confirmed that the relative power or discretion over the board and employees is positively related to CWPR.

In China, after Lu Rui ${ }^{[3]}$ (2007), Fang Junxiong ${ }^{[6]}$ (2011) took the general public companies in China as the sample and empirically found that the enlargement of CWPR is dynamically derived from the asymmetry change of executive compensation and employees compensation relative to firm performance, which is caused by the use of CEO power. Liu Xing and Peng Cheng ${ }^{[7]}$ (2012) then took Chinese state-owned public companies as the sample and again empirically found the application of CEO power theory in explaining the forming process of CWPR in state-owned companies in China. Xiao Dongsheng, Gao Shijia and Xie Hefeng ${ }^{[8]}$ (2014) found CEO power is an important factor in the process of determining the gap between the executives and employees, and further argued that the pay gap made by the excessive use of CEO power has a negative effect on the company's growth. Changzheng Zhang, Xin Mu and Zhuoqin Gao ${ }^{[9]}(2015)$ took the Chinese listed companies as the sample and empirically found that there is some positive relationship between CWPR and CEO power by adopting the muti-linear regression analysis.

In American, shortly after Wade, J. B. et al. ${ }^{[4]}(2006)$, Shin Taekjin ${ }^{[10]}$ (2008) analyzed pay disparities between executive managers and rank-and-file workers at large United States corporations. Using a sample of the 254 largest U.S. Corporations during the period of 1992-2005, the analysis suggested that CEO' power and functional backgrounds affect pay disparities between top-five executive managers and average workers within companies. Firms managed by CEO with longer tenure (and thus a higher CEO power), paid executives more, paid workers less, and had 
greater pay disparities compared to the firms with shorter-tenure CEO. Olubunmi F. et al. ${ }^{[11]}$ (2013) further took American public enterprises as the data source, and empirically confirmed the applicability of CEO power theory in explaining the forming process of CWPR in American.

Discussion on the Effect of Each Dimension of CEO Power on CWPR. The past literature ignored the differences of each dimension of CEO power. CEO power is a complicated, comprehensive and dynamic concept with multiple dimensions. Each dimension has its own characteristics and thus has different effects on the formation of CWPR. The ignorance of previous literature on this point leaves much room for our study to move forward this topic in depth.

CEO power can be derived from many aspects, i.e., the industry features, the legitimate positions, the operable resources and the share ownership. CEO power derived from industry features (CPIF) equals to the original meaning of 'CEO discretion', which means the action latitude of CEO delegated by the industry features no matter who the CEO is or which company he belongs to. CEO power derived from legitimate positions (CPLP) refers to formal authority power legally contracted onto or attached to the CEO position in a hierarchical organization. CEO power derived from operable resources (CPOR) refers to the discretionary behavior latitude delegated by the available resources for CEO, especially the fluid assets in the charge of CEO. CEO power derived from share ownership (CPSO) comes from the sense of being the owner of the firm and the consequent sense of trust from both the shareholders and the board.

Effect of CPIF on CWPR. As for the effect of CPIF on CWPR, we argue it is positive. Firms with higher CPIF means they run in an industry of dynamic, dangerous and competitive features which would not only give CEO more discretion in business issues, but also demand higher expenditure of time and energy of CEO and require CEO to be more knowledgeable and capable in running business. The extra effort and expenditure of CEO can be relative easily observed and recognized by the employers, while that of the common employees usually will be ignored by CEO and the employers, because on one side, the employers pay most of their attention on CEO and the other executives while ignoring employees, on the other side, the employees have much lower bargaining power relative to CEO. Besides, a CEO can also exert power by exploiting resource dependence (Pfeffer \& Salancik, 1978)[12]. A CEO might have unique access to resources that are valued by the firm, such as connections to customers, regulatory agencies, or innovative technologies. And highly competitive industry will bring more risks, the risk preference CEO tend to set up a high lever of compensation for high yield is always accompanied with high-risk. So CEO who is in an industry of competitive features has much stronger bargaining power relative to employees. Therefore, with the increase of CPIF, executive compensation will increase faster than that of employee compensation, and thus CWPR will be enlarged. Thus we get proposition 1 (P1) as follows.

P1: CPIF has positive effect on CWPR.

Effect of CPLP on CWPR. As for the effect of CPLP on CWPR, we propose it's a positive one. Managerial power theory predicted that the concentration of decision-making power in individual leads to more power (Finkelstein \& D'Aveni, 1994) ${ }^{[13]}$ Organizational theorists have long recognized the importance of CPLP in organizations. CEO with higher CPLP can also exert significant power over rank-and-file employees. As the leader at the top of the hierarchy, CEO can draw on their formal authority to make managerial decisions and control the bargaining power of the labor. In principle, executives with higher CPLP have a direct and unilateral power over employment of workers. Also, in larger, and more complex organizations, CEO can easily gather systematic information about employee behaviors and corporate operations, while controlling how much information that they would like to share with the employees. Through such a power base, CEO with higher CPLP has a considerable impact on the level of compensation for rank-and-file workers. No matter for the purpose of satisfying CEO' self-interest or the reason of underestimating employees' contribution while overestimating their own contribution, CEO with more power, can lead to more influence over the pay setting process (Ungson \& Steers, 1984) ${ }^{[14]}$. We therefore hypothesize, CEO with higher CPLP will enlarge CWPR. Thus we get P2 as follows.

P2: CPLP has positive effect on CWPR. 
Effect of CPOR on CWPR. As for the effect of CPOR on CWPR, we predict it's a positive one. The higher CPOR CEO holds, the greater possibility or discretion for him/her to attract higher extra rents from resource operation will be. Even CEO with higher CPOR attracts less rents from per unit resources than a peer with lower CPOR, however, as the total quantity of operable resources of the former is much larger, then CEO will get an obvious increase in compensation, while leaving employees compensation change a little. In addition, CEO tend to have a self-interested behavior when he holds a high CPOR, and use mandatory and unreasonable means to force employees to passively accept the control, which making employees have a lower bargaining power (Dai bin, 2012 ${ }^{[8]}$ Consequently, CWPR would be enlarged so naturally that can't be perceived to be very unacceptable by employees. Besides, CEO can become powerful through informational resource advantage. A greater familiarity with the company's business, internal information of organization, and technical expertise in operations can provide CEO with significant power over decision-making processes, including compensation determination. Thus we get $\mathrm{P} 3$ as follows.

P3: CPOR has positive effect on CWPR.

Effect of CPSO on CWPR. As for the relationship between CPSO and CWPR, we predict that CPSO has no significant effect on CWPR. The ownership can provide CEO more discretion in decision-making, since each stakeholder believes the good motives of such CEO to a better degree. In the view of stakeholder, as the owners, CEO will try their best to maximize the interests of their own firm, since their interests are closely linked with shareholders. Therefore, CEO with higher CPSO seemingly have to obey the expectations of the stakeholders, among which employees are included, both subjectively willing to and objectively forced to. Since they do not know exactly how CWPR affects firm performance, they have no motive to enlarge CWPR too much by using their CPSO. Besides, since CEO with higher CPSO have received a certain long-term rewards, i.e. share rewards, while employees have received much less, they will restrain CWPR in cash compensation in case of producing too much higher outrage costs, especially from the employees. Thus we get P4 as follows.

P4: CPSO has no significant effect on CWPR.

\section{Conclusion}

The relationship between CEO power and CEO-worker pay ratio (CWPR) has brought widespread attention in the process of corporate governance. In recent years, the phenomena of CEOs' 'high salary' and thus too large CWPR have been increasingly questioned. With the steady improvement of corporate governance mechanism, practically the government departments have issued a serious of remuneration control policies, and theoretically the research on the CEO power and CWPR has drawn widespread attention in the academic circles. However, the past literature only studied the antecedents of the enlargement of CWPR, and the forming mechanism of the excess CWPR is seemingly still a "black box". As for the measure of CEO power, they mainly focused on either industry-level or firm-level indicators, while ignoring the multiple dimensions of CEO power. Based on the review of theory and literature, this paper decomposes the concept of CEO power into four different dimensions, respectively CEO power derived from industry features (CPIF), CEO power derived from legitimate positions (CPLP), CEO power derived from operable resources (CPOR), CEO power derived from share ownership (CPSO), and further discusses the effect of each dimension on the formation of CWPR respectively. The greatest contribution of this paper is to find that effects of different dimensions of CEO power on CWPR have distinct intensities, because of different motivations. Though this study makes a good contribution to this field by designing different dimensions of CEO power, there is still a further empirical study to be done, since this study is just a theoretical exploration on the relationship between CEO power and CWPR from a multi-dimensional perspective.

\section{Acknowledgements}

This research was supported by Projects of the National Social Science Foundation of China under 
the Grant "15BGL109", the Scientific Research Foundation of Ministry of Education of the PRC in Humanities and Social Sciences under Grant "14YJA630089" and "13YJAZH123", and the Shaanxi Social Science Foundation under Grant "2014P04", and National Natural Science Foundation of China under Grant "71402136".

\section{Reference}

[1] Sreedhari D. Desai, Donald Palmer, Jennifer M. George., \& Arthur P. Brief. When Executives Rake In Millionns: The Callous Treatment of Lower Level Employees, Information on http://ssrn.com/abstract=1612486. 2011.

[2] Donovan A. McFarlane. Gaps in Executive and Worker Compensation as an Organizational and Management Challenge[J]. Journal of Entrepreneurship and Business Innovation, 2015, 2(1).

[3] Shao Bin, Duan Yanxia, Zhang Jinyu, \&Gao Chuang. Top Management Team Pay Gap’ s Mechanism and Its Incentive Effect from the Perspective of Managerial Power[J]. soft science, 2014, 09(28): 87-90. (in Chinese).

[4] Wade, J.B., O’ Reilly III, C.A. and Pollock, T.G. Overpaid CEOs and underpaid managers: Fairness and executive compensation[J]. Organization Science, 2006, 17: 537-544.

[5] Lu Rui. Managerial Power, Compensation Gap and Performance[J]. South China Journal of Economics, 2007, 7: 60-70. (in Chinese).

[6] Fang Junxiong. Managerial Power and Asymmetry of Compensation Change in China's Public Companies[J]. Economic Research Journal, 2011,4: 107-120. (in Chinese).

[7] Liu Xing, Peng Cheng. Executive Control Rights, Capital Expansion, and Financial Risk-Evidence from State-owned Listed Companies in China[J]. Research on Economics and Management, 2012, 5: 20-30. (in Chinese).

[8] Xiao Dongsheng, Gao Shijia, Xie Hefeng. Executive-employee Compensation Gap: Managerial Power and Enterprise' Growth-An Empirical Study based on the Panel Data of Listed SMEs[J]. East China Economic Management, 2014, 28(05): 117-122. (in Chinese).

[9] Chang-zheng Zhang, Xin Mu, \&Zhuo-qin Gao. Manipulation effects of managerial discretion on executive-employee pay gap: A comparative study between the senior CEOs and the fresh CEOs, Corporate Board: Role, Duties and Composition, 2015, 11(3): 43-66.

[10] Shin Taekjin. Working in Corporate American: Dynamics of Pay at Large Corporations, 1992-2005[M]. University of California. 2008.

[11] Olubunmi Faleye, Ebru Reis, \& Anand Venkateswaran. The determinants and effects of CEO - employee pay ratios[J]. Journal of Banking \& Finance, 2013, 37(8): 3258 - 3272.

[12]Jeffrey Pfeffer, Gerald R. Salancik. Who Gets Power-and How They Hold on to It: A Strategic-Contingency Model of Power[J]. Organizational Dynamics, 1978, 3(3): 3-21.

[13]Finkelstein, D' Aveni. CEO duality as a double-edged-sword-How boards of directors balance entrenchment avoidance and unit of command[J]. Academy of Management Journal, 1994, 37: 079-1108.

[14]Ungson, G. R., \& Steers, R. M. Motivation and politics in executive compensation[J]. Academy of Management Review, 1984, 9: 313-323. 